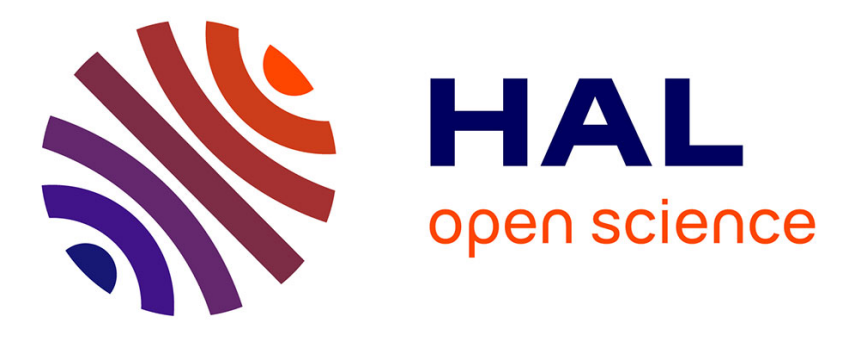

\title{
Sub-clinical infection with Salmonella in chickens differentially affects behaviour and welfare in three inbred strains
}

Michael Jeffrey Toscano, Leanne Sait, Frieda Jørgensen, Christine J Nicol, Claire Powers, Michael Bailey, Thomas Humphrey

\section{To cite this version:}

Michael Jeffrey Toscano, Leanne Sait, Frieda Jørgensen, Christine J Nicol, Claire Powers, et al.. Sub-clinical infection with Salmonella in chickens differentially affects behaviour and welfare in three inbred strains. British Poultry Science, 2010, 51 (06), pp.703-713. 10.1080/00071668.2010.528748 . hal-00652142

\section{HAL Id: hal-00652142 \\ https://hal.science/hal-00652142}

Submitted on 15 Dec 2011

HAL is a multi-disciplinary open access archive for the deposit and dissemination of scientific research documents, whether they are published or not. The documents may come from teaching and research institutions in France or abroad, or from public or private research centers.
L'archive ouverte pluridisciplinaire HAL, est destinée au dépôt et à la diffusion de documents scientifiques de niveau recherche, publiés ou non, émanant des établissements d'enseignement et de recherche français ou étrangers, des laboratoires publics ou privés. 


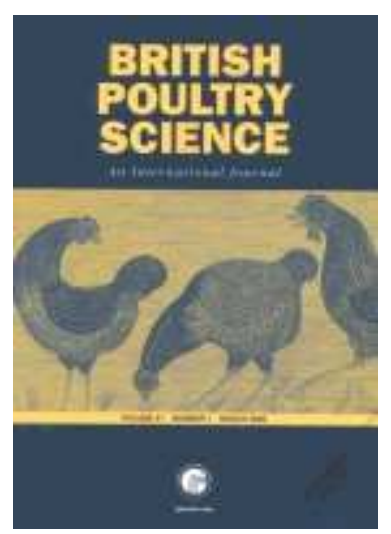

\section{Sub-clinical infection with Salmonella in chickens differentially affects behaviour and welfare in three inbred strains}

\begin{tabular}{|r|l|}
\hline Journal: & British Poultry Science \\
\hline Manuscript ID: & CBPS-2009-059.R2 \\
\hline Manuscript Type: & Original Manuscript \\
\hline Author: & 19 -Mar-2010 \\
\hline Complete List of Authors: & $\begin{array}{l}\text { Toscano, Michael; University of Bristol, Department of Clinical } \\
\text { Veterinary Science } \\
\text { Sait, Leanne; University of Bristol, Department of Clinical } \\
\text { Veterinary Science } \\
\text { Jørgensen, Frieda; University of Bristol, Department of Clinical } \\
\text { Veterinary Science } \\
\text { Nicol, Christine; University of Bristol, Department of Clinical } \\
\text { Veterinary Science } \\
\text { Powers, Claire; Institute of Animal Health, Compton Laboratory } \\
\text { Bailey, Michael; University of Bristol, Department of Clinical } \\
\text { Veterinary Science } \\
\text { Humphrey, Thomas; University Of Liverpool, Leahurst Campus, } \\
\text { National Centre for Zoonosis Research }\end{array}$ \\
\hline Keywords: & \begin{tabular}{l} 
Behaviour, Immunology, Microbiology, Physiology, Salmonella \\
\hline
\end{tabular} \\
\hline \hline
\end{tabular}

\section{SCHOLARONE ${ }^{\text {IM }}$ Manuscripts}


Sub-clinical infection with Salmonella in chickens differentially affects behaviour and welfare in three inbred strains

I M. J. TOSCANO, L. SAIT, F. JØRGENSEN, C. J. NICOL, C. POWERS ${ }^{1}$, A. L. SMITH $^{2}$, M. BAILEY AND T. J. HUMPHREY ${ }^{3}$

Animal Welfare and Behaviour Group, University of Bristol, Langford, ${ }^{1}$ Institute for Animal Health, Compton Laboratory, Compton, ${ }^{2}$ Department of Zoology, Tinbergen Building, University of Oxford, Oxford, ${ }^{3}$ National Centre for Zoonosis Research, University of Liverpool, Leahurst Campus, Neston, England

Running Head: SUB-CLINICAL INFECTION WITH SALMONELLA

Correspondence to Dr Michael Toscano, University of Bristol, Division of Farm Animal Science, Husbandry Building, Langford, Bristol, North Somerset BS40 5DU UK.

Tel; +44 0117-331-9062

Fax : +44 0117-928-9582

Email:mj.toscano@bris.ac.uk

Accepted for publication May 32010
Deleted: Full Title:II

Formatted: Font: Bold

Formatted: Font: Bold

Deleted: qI

II

Authors:

\begin{abstract}
Much evidence exists detailing how animals respond to pathogen challenge, yet information explaining how the various behavioural, immunological, and physiological systems in chickens interplay during such challenges remains limited.

2. To gain an understanding of this interplay while controlling for genetic variation, the current study collected a variety of behavioural, physiological and immunological measures from three inbred lines (P, 0 and $\mathrm{N}$ ) of laying hens before and after a subclinical infection with Salmonella enterica Typhimurium at $56 \mathrm{~d}$ of age. For comparison, an equal number of control birds were inoculated with a Salmonella-free broth. To identify an underlying profile, which might result in reduced susceptibility to infection, data were also collected in the pre-infection period. Post-infection blood and faeces were collected at 1-d post infection (dpi) and faeces again at $8 \mathrm{dpi}$. Animals were killed $15 \mathrm{~d}$ after infection and faeces, caecal contents, and spleen were examined for the presence of salmonella.
\end{abstract}


SUB CLINICAL INFECTION WITH SALMONELLA

3. Statistical analysis was performed to identify pre- and post-infection differences between genetic lines, changes in bird behavioural patterns between the two periods, and associations between a positive test for salmonella and the various response measures.

4. Tissues from Line P birds were more often negative for salmonella than those from birds of other lines, though this was inconsistent and tissue-dependent. The P line was also characterised by relatively greater serum concentrations of immunoglobulins at $1 \mathrm{dpi}$ and $\alpha_{1}$-acid glycoprotein at $15 \mathrm{dpi}$. In addition, $\mathrm{P}$ line birds were more timid and their growth was reduced during the pre-infection period suggesting the possibility of a profile with reduced susceptibility to the bacterial challenge. 5. The current work has identified correlations between attributes of chicken strains and improved clearance. Future work using hypothesis-based testing will be required to determine whether the identified correlations are causally related.

\section{INTRODUCTION}

There is increasing government and public pressure on agriculture to provide environments that ensure good animal health and welfare. Given the banning, or discouragement, of prophylactic antibiotic use, identifying how an animal adapts to infection is an area where production must meet government and public demands for enhanced animal health. In terms of animal welfare, a dramatic decrease in health, or a method of coping that is either ineffective or detrimental to long-term fitness in response to a perceived or actual challenge, is likely to have a detrimental impact (Dawkins, 1990; Broom, 1991). Thus it is important to assess not only the final impact of an illness (survival, weight loss, etc.) but also the means by which an animal adapts to infection. Recent work has suggested that particular coping styles of animals are related to immunity and disease susceptibility (Koolhaas 2008) indicating a differentiation of responses with associated outcomes. By identifying the genetic contribution to coping style and the innate means that are most important for animals to overcome or avoid infection, producers may be able to select genotypes that are more resistant to or deal with infection in a manner that is less costly to health and welfare.

Our experiment focused on Salmonella, which causes an infection often described as 'subclinical', because poultry frequently appear to show little to no behavioural or pathological symptoms (EFSA, 2006). However, we suggest that, by measuring a broad set of indicator variables, it may be possible to detect and characterise flock responses to infection and to determine how subtle physiological and behavioural changes within individual birds interact to produce a particular outcome. A greater understanding of the overall impact of apparently 'sub-clinical' infections may also facilitate the design of environments that exploit an animal's natural ability to reduce risks of infection, resulting in improved animal health and welfare. The current study used three distinct genetic strains of poultry in an effort to characterise between- and within-strain variation in indicators of competitive ability, glucocorticoids, inflammatory protein, antigen-specific immunoglobulins and bacterial load in response to a Salmonella challenge.

Of the three genetic lines (referred to as $\mathrm{P}, 0$ and $\mathrm{N}$ ), line $\mathrm{N}$ is the most studied and has been used in investigations of Salmonella resistance (Bumstead and Barrow, 1988; Wigley et al., 2002; Tilquin et al., 2005). Line $\mathrm{N}$ has been shown to be relatively resistant to Salmonella infections (Bumstead and Barrow, 1988), though resistance varied with age and subspecies (Tilquin et al., 2005). Published information on salmonella resistance in lines $\mathrm{P}$ and 0 are not available. Each of the 
SUB CLINICAL INFECTION WITH SALMONELLA

lines is known to be susceptible to a wide range of diseases, although two were originally selected for resistance/susceptibility to Marek's disease virus (lines $\mathrm{N}$ and $\mathrm{P})$ and lack of endogenous avian leukosis virus (ALV) genes (line 0). Breeding coefficients range from $0.5(\mathrm{~N})$ to $0.6(\mathrm{P}$ and 0$)$. Our choice of line was based on an unpublished experiment by our group comparing the three strains that found different suseptibilities to enteric Salmonella colonisation, as well as evidence that each strain exhibited different behavioural profiles, for example, line $\mathrm{P}$ appeared more flighty.

Our expectation was that genetic lines would differ in the collected measures and indicate a variation in immune function, behaviour and physiology that might relate to pathogen presence. Data were interpreted in a manner that sought to develop profiles of genetic strains to identify potential causal relationships between responses and salmonella susceptibility for future experimental work. We also aimed to determine the extent of correlations between the measured responses and the extent of bacterial invasion into infected tissues in individually challenged birds.

We predicted that decreased susceptibility to infection would be associated with a response profile that limited the invasion and spread of the pathogen while conserving energy. Specifically, birds with reduced infection would have a response characterised by: increased serum glucocorticoid, inflammatory protein, glucose and creatinine concentrations while weight gain, general behavioural activity and behaviour during competition tests would be reduced. Our predictions are based on the assumption that birds with reduced indications of infection will respond by directing resources towards supporting the immune response, for example, glucocorticoids help to mobilise stored energy (Genuth, 1998). Following the acute response to infection and reflecting the chicken's effort to reduce salmonella colonisation (Revolledo et al., 2009), increased immunoglobulin concentrations would indicate a more robust immune response.

\section{MATERIALS AND METHODS}

\section{Animals and infection}

The three inbred chicken lines ( $\mathrm{P}, 0$, and $\mathrm{N}$ ), all single-comb White Leghorns, were maintained at the Institute for Animal Health (IAH, Compton Laboratories, Berkshire UK). Line 0 was initiated in 1979, was SPF and was selected for the absence of endogenous ALV-E proviral genes and for resistance to endogenous but susceptibility to exogenous ALV (Bacon et al., 2000). Line N, housed at IAH, originated at Cornell University, was obtained from the Avian Disease and Oncology Laboratory, USDA, in 1982 and was highly resistant to Marek's disease (MD). Line P, housed at IAH and obtained from Lelystad in 1996, originated at Cornell and was highly susceptible to MD (Cole, 1968; Bacon et al., 2001).

Female and male birds were hatched at IAH and transported to the University of Bristol School of Veterinary Science within $3 \mathrm{~d}$ of hatching. Birds of the three lines were randomly divided into two groups placed in separate large rooms where they were maintained in mixed-strain groups of approximately 100 birds ( 1 group/room) with ad-libitum access to water and food $(160 \mathrm{~g}$ protein $/ \mathrm{kg})$. At $35 \mathrm{~d}$ of age, the birds were sexed and female birds only were placed into 4 groups in rooms that each contained 4 pens. Each pen measured $1.5 \times 1.22 \mathrm{~m}$ and had open top feeders and drinkers that provided ad libitum food and water. Pens were also provided with a perch and wood shavings approximately $60 \mathrm{~mm}$ in depth. Three of the 4 pens were allocated 6 pullets from a single line, that is, 6 birds per pen. The fourth pen contained two pullets of each strain ( 2 line $\mathrm{P}, 2$ line 0 and 2 line $\mathrm{N}$ ), though a shortage of line $\mathrm{P}$ birds resulted in only a single bird being placed in two of the 4 pens. The 
SUB CLINICAL INFECTION WITH SALMONELLA

fourth pen was included in the experimental design $\mathrm{P}$ as part of a separate study and results pertaining to these mixed genotype pens were not included in the present analyses. Feeders were topped up and pens cleaned daily by animal care staff. Light was provided between 07.00 and 19.00 and the temperature was maintained between 16 and $22^{\circ} \mathrm{C}$.

At $56 \mathrm{~d}$ of age (hereafter referred to as $0 \mathrm{~d}$ post infection (dpi)), all birds in two of the 4 rooms received $1.8 \times 10^{8}$ of Salmonella enterica Typhimurium 4/74 via oral gavage (SAL treatment; $\mathrm{n}=36$ birds not including mixed genotype pens). Our choice of dosage was based on previous studies by the authors and others comparing dose ranges (Barrow et al., 2004; Beal et al., 2004) and was directed at achieving a subclinical infection. Birds in the remaining two rooms served as a control (CON treatment; $\mathrm{n}=36$ birds not including mixed genotype pens) and received an equivalent volume of salmonella-free broth. Personnel entering the facility were required to wear boiler suits and rubber boots. Boots were dipped into an antimicrobial bath before entering rooms. In addition, to minimise accidental infection of controls, rooms of each treatment were located in identical suites separated by a central corridor.

\section{Behavioural observations}

During the period between allocation to the various groups at six weeks of age and post-mortem examination seven weeks later, behavioral differences between strains, homogeneity of strains in the pen and response to salmonella infection were examined.

Competition for limited resources requires the expenditure of energy and involves social risk. It is therefore a good discriminator between individual animals and provides a response measure that should be sensitive to any detrimental effects of infection. We devised a resource competition test and used this to (i) examine strain differences (ii) determine whether inter-bird differences in resource competition during the pre-inoculation period were associated with infection outcome in SAL birds and (iii) monitor the effects of infection by comparing resource competition behaviour pre- and post-salmonella challenge.

For identification purposes, all birds had a numbered wing band. To ease identification of birds within a pen, each bird was also marked on its back using stock marker in a unique pattern. In the week before resource competition tests began, birds were cclimatized to the dish on which food would later be presented and to the observer by performing the procedure twice, though no measurements were taken. The resource competition test was conducted on three occasions over two days prior to infection (on days -4 and -3 dpi) and on three occasions over two days afterwards (between days +3 and $+10 \mathrm{dpi}$ ). For the test, a single observer approached the pen and waited immediately outside it for $60 \mathrm{~s}$ to allow the birds to acclimatise to her presence. At the end of this period, the observer placed a small ceramic dish (diameter: $60 \mathrm{~mm}$ ) that contained several waxworms (Achroia grisella) in a corner of the pen. Following worm placement, birds within a pen were continuously observed for 5 min during which frequency of behaviours were recorded. Observed behaviours were mutually exclusive and included: aggressive pecks, running, approaching worms, feeding on and pecking at worms, feeding on pellets, sitting on feeder, litter pecking, perching, preening, sitting and/or standing alert, threats, drinking, ground scratching and flying. At the conclusion of the test, all data were summed across the 5-min period and entered into a spreadsheet for later analysis. Data were further consolidated into pre- and post-infection periods in an effort to produce data with a normal distribution. Behaviours not included in analysis due to infrequent 
SUB CLINICAL INFECTION WITH SALMONELLA

occurrences were aggressive pecks, sitting on the feeder, mild pecks, sitting alert, threats and flying. Reported units are the total number of times the behaviour was performed during the observation period.

To measure the impact of infection on behaviour, we compared the general behavioural profile of each treatment (SAL and CON) one week after infection, using scan sampling techniques. Each pen was filmed for $3 \mathrm{~h} \times 3$ times in the week following infection using colour closed-circuit TV cameras. Each three-hour segment of footage was observed using 10-min interval scan samples for each animal where the animal's activity was classified using the mutual exclusive categories of active, inactive or feeding/drinking. The total number of times each category was performed by an individual during each of the three-week sections of footage was expressed as a fraction of the total number of observations (that is, 10-min intervals) made throughout that section.

\section{Collection of faeces, blood and bird weight}

Faeces were collected at $-13,-6,+1$ and +8 dpi. To minimise stress associated with collection, faeces were collected passively by placing the animal in a custom built faecal collection unit. The unit consisted of 4 plywood rectangular panels $(120 \times 160$ $\mathrm{mm}$ ) connected by 4 wooden dowels at each corner and separated by a gap of $160 \mathrm{~mm}$ resulting in a three dimensional rectangle. The base and the sides of the unit were wrapped in chicken wire. Units were placed alongside one another during collections providing visual contact with birds in adjacent units. Birds of the same pen underwent the collection protocol at the same time. Birds were placed individually in the collection units and after 20 min the birds were returned to their home pen by

which time approximately $90 \%$ of birds had defaecated in the area below allowing for samples to be collected and placed on ice At the conclusion of collections, samples were placed in a $-80^{\circ} \mathrm{C}$ freezer until analysis. Collections were begun at approximately $09.00 \mathrm{~h}$ and concluded within $3 \mathrm{~h}$ to minimise effects of the natural diurnal rhythm of the glucocorticoid on sample variation. Room-to-room collection order was changed for each of the time points.

Blood was collected at $-6,+1$ dpi and +15 dpi (post-mortem). Room-to-room collection order was changed for each of the time points. For serum collection at -6 and +1 dpi, approximately 1-3 $\mathrm{ml}$ of whole blood was removed from a wing vein using a syringe and $25 \mathrm{G}$ needle, injected into an empty vacutainer, and placed on ice. Samples were refrigerated for $24 \mathrm{~h}$, centrifuged at $700 \mathrm{~g}$ for $10 \mathrm{~min}$, and the serum removed and portioned appropriately. Serum collected postmortem was separated as described above.

All birds were weighed at -21 and -9 dpi. The change in weight for each bird was obtained by calculating the difference between these two weights.

\section{Hormone and metabolite analysis}

Glucocorticoid metabolites were determined in faeces using a commercially available assay kit (07-120-103, MP Biomedicals, Illkirch, France). Samples were assayed in duplicate and any resulting in a coefficient of variation (CV) greater than $10 \%$ were re-determined. For extraction of metabolites, a protocol adapted from Denhard et al. (2003) was used. Approximately $0.3 \mathrm{~g}$ of sample was combined with $5 \mathrm{ml}$ of $90 \%$ methanol and manually separated by vortexing and tapping for $10 \mathrm{~s}$. All samples were individually weighed immediately before placement into methanol. Samples were shaken for $30 \mathrm{~min}\left(130 \mathrm{rpm}, 25^{\circ} \mathrm{C}\right)$ with an orbital shaker and then centrifuged $(10 \mathrm{~min}, 1200 \mathrm{~g}$ ). Supernatant $(4 \mathrm{ml})$ was transferred to a new tube containing $5 \mathrm{ml}$ of water, thus diluting samples to $40 \%$ methanol. After completion of the assay, the 
SUB CLINICAL INFECTION WITH SALMONELLA

resulting metabolite concentration was multiplied by 113.5 to obtain the concentration of the initial dilution and then divided by the weight of the faecal sample. Resulting

| units are expressed as ng glucocorticoid metabolites/g of faeces collected.

Commercially available assays were used to determine the concentration of various serum constituents including: $\alpha_{1}$-acid glycoprotein (AGP) (P0801-1, Cardiotech Services, Louisville, KY, USA), glucose (1070-125, BDS International Diagnostics, Schwetzingen, Germany), and creatinine (500701, Cayman Chemical, Ann Arbor, MI, USA).

Enzyme-linked immunosorbent assay (ELISA) of immunoglobulins

For production of soluble salmonella lysate antigen, preparations of soluble $S$. enterica Typhimurium 4/74 nalr lysate (STAgP) were prepared as described by Beal et al. (2004). Overnight cultures of STm 4/74 nalr were used to inoculate a $250 \mathrm{ml}$ Erlenmeyer flask containing $100 \mathrm{ml}$ of LB medium and incubated overnight at $37{ }^{\circ} \mathrm{C}$ in an orbital incubator $(150 \mathrm{rpm})$. Bacterial cells were pelleted $(4000 \mathrm{~g}$ ) and washed twice with an equal volume of phosphate-buffered saline (PBS; $\mathrm{pH}=9.6$ ) and resuspended in $20 \mathrm{ml}$ PBS. The bacterial suspension was subjected to three freeze-thaw cycles in liquid nitrogen followed by sonication $(9 \times 20 \mathrm{~s}$ bursts with 1 min cooling on ice between bursts) in a $10 \mathrm{ml}$ volume at an amplitude of $15 \mu \mathrm{m}$ using a Soniprep 150 (MSE Scientific Instruments, Crawley, UK). The suspension was centrifuged at $4080 \mathrm{~g}$ for $20 \mathrm{~min}$ at $4^{\circ} \mathrm{C}$ followed by centrifugation of the supernatant at $30000 \mathrm{~g}$ for $20 \mathrm{~min}$ at $4^{\circ} \mathrm{C}$ to remove insoluble fractions. The supernatant was retained. Protein concentrations of the soluble antigen preparation were measured using the Bradford protein determination kit (Merck, Poole, UK) and aliquots were frozen $\left(-20{ }^{\circ} \mathrm{C}\right)$ until used.

Concentrations of serum antibody (IgM and $\mathrm{IgY}$ ) reactive against STAgP were measured by ELISA as described by Beal et al. (2004). Flat-bottomed 96-well ELISA plates (BD Biosciences, Oxford, UK) were coated overnight at $4{ }^{\circ} \mathrm{C}$ with $50 \mu 1$ per well of STAgP preparation (diluted to $14.73 \mu \mathrm{g} / \mathrm{ml}$ in carbonate/bicarbonate buffer (pH 9.6)). Plates were washed with PBS Tween-20 (0.05\% by volume) (PBST) before blocking with PBS-T supplemented with 3\% skimmed milk powder for $1 \mathrm{~h}$ at $37^{\circ} \mathrm{C}$. Serum samples were diluted to $1: 400$ in blocking buffer (for both $\operatorname{IgY}$ and IgM detection) and $50 \mu 1$ per well was added to the plates before incubation at $37^{\circ} \mathrm{C}$ for $1 \mathrm{~h}$. Plates were washed and bound immunoglobulins were detected by incubation at $37{ }^{\circ} \mathrm{C}$ for $1 \mathrm{~h}$ with horseradish peroxidase conjugated to either goat anti-chicken IgM (1:1000) (Serotec, Oxford, UK) or rabbit anti-chicken IgY (1:2000: Sigma) diluted in blocking buffer $(50 \mu \mathrm{l}$ per well). Plates were washed and a solution containing 2,2-azino-di(3-ethylbenzothiazoline-6-sulphonate) (ABTS) and hydrogen peroxide $(50 \mu \mathrm{l} /$ well $)$ was added. Plates were incubated at room temperature in the dark for 30-60 min and the reaction was stopped by addition of $1 \%$ SDS (50 $\mu 1$ per well). Absorbances were read at $405 \mathrm{~nm}$ on a Benchmark microplate reader (Biorad, Hemel Hempstead, UK).

\section{Post mortem examination and microbiological analysis}

At +15 dpi, all birds were killed. The presence of salmonella recovered from homogenised spleen and caecum were determined by plating on to modified Brilliant Green Agar (mBGA) using two samples per site. The limit of accurate detection was $2 \log _{10} \mathrm{cfu} \mathrm{g}^{-1}$ tissue and any sample containing fewer bacteria was pre-enriched in buffered peptone water (CM509, Oxoid Ltd, Basingstoke, UK) followed by selective enrichment in Rappaport Vassiliadis broth (CM669, Oxoid Ltd, Basingstoke, UK). 


\section{Statistical analysis}

All non-microbiological data (body weight, change in weight, $\operatorname{IgM}, \operatorname{IgY}$, faecal corticosterone metabolites, glucose, AGP, and behaviour) were checked to assume a normal distribution and log transformed if necessary. Any data requiring log transformation were back-transformed for presentation of data and variation presented as the width of the $95 \%$ confidence interval. PROC GLM of SAS (SAS Inst. Inc., Cary NC) was used for analysis and the following independent variables were included in the model: strain nested in treatment by room combination, strain, treatment, and strain by treatment interactions. Strain nested in treatment by room combinations was identified as a random variable by the RANDOM statement of GLM and the TEST option was used to generate the appropriate test statistic for model components (Littell et al., 1998). Separate analysis was conducted for measures collected on different days to avoid multiple levels of nesting. $P$-values equal to or less than 0.05 were considered statistically significant.

To identify changing patterns in birds due to infection, a paired $t$-test (SAS Inst. Inc., Cary NC) was used to compare the average of each individual's behaviour in the pre- and post-infection period. Comparisons were made separately for the SAL and $\mathrm{CON}$ treatments to determine whether the changes could be attributed to age or time effects rather than treatment.

To identify patterns of responses associated with the site(s) of isolation of $S$. Typhimurium post-mortem, animals in the SAL treatment were identified as either positive or negative based upon the presence of Salmonella for each of the collected tissues: spleen, caecum or both tissues combined. For instance, an animal that was positive in the spleen by direct plating only would be considered positive in the spleen, negative in the caecum and positive in the combined class. Resulting data were analysed using Proc GLM to identify differences between the positivity groupings in the various physiological, immunological and behavioural responses. Analysis was only conducted for the SAL treatment; the model was similar to the above with the exception that genetic strain was nested in room only and treatment was not included in the model.

Microbiological data from the SAL treatment were analysed using Fisher's Exact test of Proc FREQ within SAS (SAS Inst. Inc., Cary NC) to determine whether the number of animals positive for Salmonella was independent of genetic strain, as would be expected under the null hypothesis. Fisher's Exact test is intended for data sets where the expected frequency of 1 or more cells is less than 5 (Severino, 2000). Positivity analysis was conducted separately for the spleen, caecum or both tissues combined. When an association between strain and positivity was found, the binomial option of Proc Freq within SAS (SAS Inst. Inc., Cary NC) was used to construct post-hoc tests that tested whether there was a statistical difference between the number of positive and negative animals of each strain within the SAL treatment. No salmonella were found in CON birds.

\section{RESULTS}

\section{Resource competition test}

During the pre-infection period, pecking of waxworms differed between genetic strains with $\mathrm{P}$ line birds exhibiting the least of these activities $(P=0.03)$. Birds of the $\mathrm{P}$ line also drank more than those from the other lines $(P=0.008)($ Table 1$)$. Feeding on waxworms occurred more frequently in the SAL treatment $(P=0.02$; data not shown; $\mathrm{SAL}=0.53 \pm 0.24, \mathrm{CON}=0.37 \pm 0.24$ ). Feeding on pellets showed a strain 
SUB CLINICAL INFECTION WITH SALMONELLA

by treatment effect where line $\mathrm{P}$ birds within the CON treatment fed more frequently than all other lines by treatments (data not shown; line $\mathrm{P}$ of $\mathrm{SAL}=2.1 \pm 0.31$, remaining treatment combinations $<0.7 \pm 0.31$ ). During the post-infection period, line $\mathrm{P}$ birds from the SAL treatment stood alert more than their CON counterparts while the opposite was seen in line 0 birds $(P<0.05)$ (Figure 1$)$. In comparing pre- and postinfection data of the resource competition test, SAL birds revealed a significant decrease in several behaviours (drinking, feeding on pellets and litter pecks) $(P<0.05)$ (Table 2) between the pre- and post-infection periods. In contrast, pecking at waxworms increased in the SAL birds $(P=0.004)$ (Table 2). Comparing the pre- and post-infection periods of the CON treatment revealed feeding on waxworms increased $(P<0.04)$. Grouping SAL birds by salmonella positivity at post-mortem examination revealed a tendency for birds that were positive in the spleen and/or caecum to perform less feeding on waxworms during the post-infection period $(P=0.07$; data not shown; Salmonella-negative $=0.9 \pm 0.6$, Salmonella-positive $=0.3 \pm 0.3$ ) .

\section{Scan samples of bird activity}

Statistical analysis from scan sample data of general bird behaviour in the week following infection showed no significant effect of treatment on activity level or feeding and drinking behaviour. Birds of line $\mathrm{N}$ were significantly less active than line 0 birds during the same period $(P<0.01$, data not shown).

\section{Glucocorticoid metabolites}

There were no line differences in faecal glucocorticoid metabolites during the preinfection period $(P>0.3)$. Birds which were to be infected with salmonella had a reduced $(P=0.04)$ concentration of glucocorticoid metabolites at -13 dpi but there was no difference $(P=0.4)$ between the CON and SAL birds at -6 dpi (Table 3$)$. During the post-infection period, no differences $(P>0.3)$ between strains were observed. Birds of the CON treatment showed a dramatic increase $(P<0.0001)$ in glucocorticoid metabolite concentration at +1 dpi, which was not observed in the SAL. By +8 dpi the glucocorticoid metabolite concentrations of the CON birds had returned to normal, so there was no longer a difference $(P=0.3)$ between treatments (Table 3). No effect of positivity was found for glucocorticoid metabolites on any of the collection dates $(P>0.1)$.

\section{$\alpha_{1}$-Acid Glycoprotein}

During the pre-infection period, line 0 birds had serum AGP concentrations that were reduced in comparison to the lines $\mathrm{P}$ and $\mathrm{N}(P<0.0001$; line $\mathrm{P}: 424 \pm 58$, line $0: 245 \pm$ 52 , line $\mathrm{N}: 445 \pm 54)$. All other pre-infection comparisons revealed no statistically significant differences $(P>0.1)$. In the post-infection period, salmonella-infected birds had a tendency for reduced AGP concentrations compared to controls $(P=0.06$, $\mathrm{SAL}=280 \pm 64 \mathrm{ug} / \mathrm{mL}, \mathrm{CON}=375 \pm 64 \mathrm{ug} / \mathrm{mL})$ at $+1 \mathrm{dpi}$. At $+15 \mathrm{dpi}$, each genetic line had different AGP concentrations that were independent of treatment with the lines $\mathrm{P}$ and 0 having the greatest and least, respectively $(P<0.05$; data not shown; line $\mathrm{P}=365 \pm 55 \mathrm{ug} / \mathrm{mL}$, line $0=162 \pm 50 \mathrm{ug} / \mathrm{mL}$; line $\mathrm{N}=253 \pm 56 \mathrm{ug} / \mathrm{mL})$. Positivity comparisons found birds which were positive for salmonella in the spleen and/or caecum at post-mortem had a reduced concentration of AGP at -6 dpi $(P=0.04)$ with a tendency for a similar pattern at $+15 \mathrm{dpi}(P=0.07)($ Fig. 2$)$. Birds which were positive for salmonella in the spleen only at post-mortem examination had a reduced concentration of AGP at $+15 \mathrm{dpi}(P=0.006)$ and a tendency to be reduced at $-6 \mathrm{dpi}(P$

Deleted: L
Deleted: '
Deleted: '
Deleted: '
Deleted: '


SUB CLINICAL INFECTION WITH SALMONELLA

$=0.07)$ (Fig. 3). All other comparisons were similar between positive and negative animals $(P>0.19)$.

\section{Immunoglobulins $\mathbf{Y}$ and $\mathrm{M}$}

Absorbance measures of the antigen-specific $\operatorname{IgY}$ and IgM during the pre-infection period did not differ between lines or treatment $(P>0.4)$. During the post-infection period, all absorbance readings for IgM (Table 4) and IgY (Table 5) indicated greater concentrations in infected birds compared to controls $\left(\begin{array}{l}P \\ 0.05\end{array}\right)$ with the exception of birds from $l$ ine $\mathrm{N}$ which were similar between treatments for $\operatorname{IgY}(P=0.09)$.

Comparison within the SAL treatment revealed that lines $\mathrm{P}$ and 0 birds had greater absorbance readings than line $\mathrm{N}$ birds for both $\operatorname{IgM}$ and $\operatorname{IgY}(P<0.002)$. All other

| comparisons between strains revealed no differences $(P>0.1)$. No effect of salmonella positivity on IgY or IgM concentrations was found within the SAL treatment during either the pre- or post-inoculation periods $(P>0.5)$.

\section{Weight and weight change}

Weight and weight change during the pre-infection period differed between all three strains at each time point. The greatest weight and weight gains $(P<0.04)$ were in line $\mathrm{N}$ followed by lines 0 and $\mathrm{P}$ (Table 6 ). Birds that were to receive salmonella were heavier at -6 dpi $(P=0.01$; data not shown; SAL: $515 \pm 11 \mathrm{~g}$, CON: $494 \pm 11 \mathrm{~g})$.

Bird which were positive for salmonella in the spleen and/or caecum post-mortem tended to weigh more at -6 dpi than birds that were negative $(P=0.07$; positive $=334$ $\pm 12 \mathrm{~g}$, negative $=293 \pm 21 \mathrm{~g}$ ). All other comparisons of positivity for the collected weights and weight gain were similar $(P>0.1)$. No weight data were collected during the post-infection period.

\section{Salmonella infections}

More birds from lines 0 and $\mathrm{N}$ were positive for salmonella when positivity for the caecum and spleen were combined $(P<0.04)$ (Table 7$)$. When findings from the spleen were considered independently, line 0 had more animals positive for salmonella $(P=0.003)$. In each of these cases, the number of negative birds was greater than the number of positive. All other comparisons between strains for the number of birds found to be positive for Salmonella were similar $(P>0.07)$.

\section{Non-significant results}

Serum glucose and creatinine concentrations were unaffected by strain, treatment, or positivity of the bird at post-mortem $(P>0.09)$.

\section{DISCUSSION}

The current work served two objectives: firstly, comparing the response of three genetically different poultry strains to a sub-clinical salmonella challenge and secondly, identifying an underlying behavioural, physiological and immunological profile within or across genetic strains that resulted in reduced susceptibility to that challenge. Genetic differences are known to influence a variety of factors that impact on disease susceptibility including gut microflora (Hart et al., 2002) and immune function (Xavier and Rioux, 2008). Despite this knowledge, many questions remain regarding how non-genetic animal factors (acquired behavioural tendencies) affect disease susceptibility or how these genetic and acquired factors may interact.

As part of our first objective, we expected that the chosen strains would differ | independently of a salmonella challenge and thus pre-infection data were collected to

Formatted: Font: Not Italic 
SUB CLINICAL INFECTION WITH SALMONELLA

determine baseline differences between strains. Consistent with our hypothesis, comparison of pre-infection measures suggested that birds from line $\mathrm{P}$ were more timid in terms of their behavioural style and exhibited a pattern of energy use that was more conservative. Our characterisation is based on line $\mathrm{P}$ birds pecking less at the waxworms, drinking more and reduced weight and weight gain compared to the other strains. With regards to drinking, line $\mathrm{P}$ drank at a frequency 5 times greater than the other lines which may reflect a lack of interest or shift in activity due to a fear of approaching the waxworms during this test rather than an actual physiological need to drink. Line $\mathrm{P}$ birds also had a higher AGP concentration than line 0 birds though similar to line N. Feeding on pellets was greatest in line $\mathrm{P}$ birds, which were to | receive salmonella, although this was likely to be a suite effect as it was not consistent across pens containing line $\mathrm{P}$ birds. Future work will be needed to identify whether a causal relationship exists between behaviour, weight gain and concentrations of inflammatory proteins during periods of positive health. If such a $\square$ relationship were found, identifying the mechanisms involved may help $\square$ producers to develop poultry lines with improved ability to overcome infections, resulting in improved animal welfare.

Because we were focussing on sub-clinical infections we did not expect a severe response following infection, although the broad measures we employed did reveal differences between treatments. Potential responses that we anticipated include a well-established collection of behaviours that animals typically adopt during infection including: reduced feeding, changes in activity and social interactions in combination with huddling, shivering and other behaviours that conserve energy and improve bodily processes to combat disease (Millman, 2007). In addition to behavioural responses during periods of illness, we also expected animals to have an immunological and physiological response including release of inflammatory proteins (such as AGP) (Holt and Gast, 2002), immunoglobulins (Beal and Smith, 2007) and glucocorticoids (Webster and Sternberg, 2004). Although our expectations were only partially met in terms of these responses, birds that received salmonella adopted a profile that was less active, with reductions in drinking, feeding on pellets and litter pecks. In the SAL treatment, pecking at waxworms increased although consumption of worms remained unchanged, suggesting a decrease in hunger motivation. In terms of an immune response, IgM and $\mathrm{Y}$ increased confirming that the infected birds were experiencing an immunological challenge. In contrast, glucocorticoids and AGP were altered in a manner that was opposite to our predictions and potential explanations are discussed below. Feeding on waxworms increased in CON birds possibly as a result of acclimatisation to the test procedure.

Following infection with salmonella, we hypothesized that genetic strains would differ in the resulting bacterial load. In support of this hypothesis, line P birds appear to have cleared salmonella more effectively as shown by the line 0 and $\mathrm{N}$ having a greater proportion of birds positive for salmonella in the combined tissue grouping (spleen and caecum). In the spleen only, a trend existed for line $\mathrm{P}$ to have a greater number of animals negative for salmonella. Although our interpretation is conjecture, the possibility exists that line $\mathrm{P}$ benefited in the form of a heightened immune response from a pre-infection profile characterized by timidity, slower growth, and a relatively high serum AGP concentration. Post-infection measures regarding line $\mathrm{P}$ appeared to further confirm the possibility of enhanced immune function for combating salmonella as suggested by the line $\mathrm{P}$ having serum concentrations of AGP and immunoglobulins that were greater than line N. Additionally, birds of the line $\mathrm{P}$ in the SAL treatment stood alert more than the $\mathrm{CON}$ treatment whereas line 0 
SUB CLINICAL INFECTION WITH SALMONELLA

displayed the opposite pattern. A profile characterized by greater production of immunoglobulins and AGP and a reduced activity level may have benefited the line $\mathrm{P}$ during the challenge.

Our findings are based entirely on correlations that are subject to interpretation but they form the basis for a subsequent hypothesis-based approach to ensure the presence of an actual relationship. For instance, line 0 birds were all positive for salmonella in terms of the spleen only and combined caecum and spleen positivity measure yet had a statistically similar immunoglobulin concentration to line $\mathrm{P}$ at +15 dpi. If our hypothesis that line $\mathrm{P}$ was adopting a profile that was effective in providing energy for immune function, we would expect that line 0 birds would have comparatively reduced immunoglobulins. It is also possible that birds in neighbouring pens or the adjacent rooms may have influenced one another, though footbaths outside the rooms and physical barriers between pens were present to minimize this possibility. Whether birds of each genetic strain are adopting different strategies with different grades of success in terms of salmonella clearance will need to be determined with future research.

In pursuit of our second objective to identify correlations between measured responses and the extent of bacterial invasion, we hypothesized that birds with a reduced bacterial load post-mortem would manifest specific changes in the measured responses. Our hypothesis was based on an expectation that these responses reflect a more aggressive immune response and, as a result, reduced invasion following infection. In support, birds negative for salmonella at in the spleen post-mortem examination had comparatively more AGP at +15 dpi suggesting that those that were better able to limit invasion had greater serum AGP concentrations. Additionally, serum AGP concentrations during the pre-infection period mirror those at $+15 \mathrm{dpi}$, supporting the concept of a profile, i.e., certain birds may have mechanisms better able to reduce invasion of bacteria before exposure. The finding that birds positive in the spleen and/or caecum at post-mortem examination tended to weigh more at $-6 \mathrm{dpi}$ also suggests that birds with reduced weight gain may benefit from improved immune function. In contrast to our findings, Holt and Gast (2002) reported a positive correlation between AGP and presence of Salmonella Enteritidis in the faeces of poultry undergoing feed withdrawal at $3 \mathrm{dpi}$. The difference in results may be related to our focus on invasiveness in tissues at a later date while the work by Holt and Gast (2002) quantified the presence of bacteria in faeces during the acute phase of infection. A greater concentration of AGP during the acute phase of infection may indicate the severity of disease while concentrations at later stages reflect an ability to clear Salmonella and limit its spread into central tissues.

In addition to those discussed above, several findings were contrary to our expectations, notably faecal glucocorticoid metabolite and AGP concentrations. Glucocorticoids are normally reported to increase in concentration following bacterial challenges (Webster and Sternberg, 2004). In contrast to this expectation, the average faecal glucocorticoids at +1 dpi in the CON animals was nearly three times greater than concentrations for either of the treatments at any other time point suggesting the $\mathrm{CON}$ animals had the most aggressive response to the imposition of treatment. Concentrations of faecal glucocorticoid metabolites are a reliable indicator of plasma glucocorticoids (Dehnhard et al., 2003), thus the collection medium is unlikely to be a factor in our findings. Nonetheless, several factors should be considered. First, although glucocorticoid metabolite concentrations were greater in CON compared to SAL animals, both treatment groups were handled and received a broth, albeit a sham broth in the former. Thus, the increased glucocorticoid metabolite concentrations 
SUB CLINICAL INFECTION WITH SALMONELLA

observed in the CON treatment at +1 dpi in comparison to the previous time points may be attributed to the handling when receiving the broth. The lack of a similar change in SAL animals may be related to our extraction method which did not employ a process to remove water content as others have reported the step to result in similar concentrations regardless of its inclusion (Wasser et al., 2000). One explanation to consider is that animals in the SAL treatment had a higher incidence of diarrhoea resulting in greater water content in their faeces. Although this would not have affected the absolute concentration of glucocorticoid metabolites in the faeces, it may have increased the weight used in calculating the concentration of metabolite/g of faeces. Secondly, there was a detectable difference in faecal glucocorticoid metabolites before treatments were applied at -13 dpi, thus there may have been a preexisting condition that was exacerbated by receiving the broth, although this is unlikely as pre-infection differences were eliminated by -6 dpi.

A second unexpected finding was a tendency for increased AGP concentrations in CON birds at +1 dpi, given that AGP is normally greater in animals undergoing a bacterial challenge (Fournier et al., 2000). The observed pattern may reflect greater clearance of AGP in the SAL treatment, although this is an untested hypothesis. In addition to the unexpected pattern seen between treatments, the magnitude of the change in concentrations suggests a minimal AGP response. Related work by Holt and Gast (2002) reported that leghorn hens infected with Salmonella Enteritidis, a different and more invasive serovar, had AGP concentrations four times greater than their control counterparts at $3 \mathrm{dpi}$. In our study, the concentration of AGP in CON animals was only 1.5 that of the SAL treatment suggesting a small difference between treatments. We had chosen a relatively low dose of salmonella to induce a subclinical response and the possibility exists that the dose used was not adequate to provoke a major response in AGP concentrations. More critically, the concentrations had actually decreased from the pre-infection concentrations observed at -6 dpi as suggested by the reported means.

In conclusion, our results suggest the existence of a coping profile involving a suite of attributes that were potentially associated with an improved clearance of salmonella. These attributes include: drinking, pecking at the waxworms during the resource competition test, weight and weight gain, serum AGP and immunoglobulin concentrations. In addition, our findings suggest that these genetic lines offer a useful resource to identify genetic and environmental influences on susceptibility to subclinical salmonella infections. Future work using hypothesis-based testing will be required to determine any causal associations of the identified correlations with improved clearance.

\section{REFERENCES}

Bacon, L. D., Hunt, H. D. \& Cheng, H. H. (2000) A review of the development of chicken lines to resolve genes determining resistance to diseases. Poultry Science, 79: 1082-1093.

Bacon, L. D., Hunt, H. D. \& Cheng, H. H. (2001) Genetic resistance to Marek's disease. Current Topics in Microbiology and Immunology, 255: 122-141.

Barrow, P.A., Bumstead, N., Marston, K., Lovell, M.A. \& Wigley, P. (2004) Faecal shedding and intestinal colonization of Salmonella enterica in in-bred 


\section{SUB CLINICAL INFECTION WITH SALMONELLA} chickens: the effect of host-genetic background. Epidemiology and Infection, 132: 117-126.

Beal, R.K. \& Smith, A.L. (2007) Antibody response to Salmonella: its induction and role in protection against avian enteric salmonellosis. Expert Review of Antiinfective Therapy, 5: 873-881.

Beal, R.K., Wigley, P., Powers, C., Hulme, S.D., Barrow, P.A. \& Smith, A.L. (2004) Age at primary infection with Salmonella enterica serovar Typhimurium in the chicken influences persistence of infection and subsequent immunity to rechallenge. Veterinary Immunology and Immunopathology, 100: 151-164.

Broom, D.M. (1991) Animal welfare: concepts and measurement. Journal of Animal Science, 69: 4167-4175.

Bumstead, N. \& Barrow, P.A. (1988) Genetics of resistance to Salmonella typhimurium in newly hatched chicks. British Poultry Science, 29: 521-529.

Cole, R. K. (1968) Studies on genetic resistance to Marek's disease. Avian Diseases, 12: $9-28$.

Dawkins, M.S. (1990) From an animal's point of view: Motivation, fitness, and animal welfare. Behavioral and Brain Sciences, 13: 1-9.

Dehnhard, M., Schreer, A., Krone, O., Jewgenow, K., Krause, M. \& Grossmann, R. (2003) Measurement of plasma corticosterone and fecal glucocorticoid metabolites in the chicken (Gallus domesticus), the great cormorant (Phalacrocorax carbo), and the goshawk (Accipiter gentilis). General and General and Comparative Endocrinology, 131: 345-352.

EFSA (2006) Trends and sources of zoonoses, zoonotic, agents and antimicrobial resistance in the European Union in 2004. European Food Safety Authority Journal, 310: 23-95.

Fournier, T., Medjoubi, N.N. \& Porquet, D. (2000) Alpha-1-acid glycoprotein. Biochimica et Biophysica Acta - Protein Structure and Molecular Enzymology, 1482: 157-171.

Genuth, S.M. (1998) The Endocrine System. In Berne, R.M., Levy, M.N., Koeppen, B.M., Stanton, B.A. (eds.) Physiology. Mosby, New York, pp. 930-964.

Hart, A.L., Stagg, A.J., Frame, M., Graffner, H., Glise, H., Falk, P. \& Kamm, M.A. (2002) The role of the gut flora in health and disease, and its modification as therapy. Alimentary Pharmacology and Therapeutics, 16: 1383-1393.

Holt, P.S. \& Gast, R.K. (2002) Comparison of the effects of infection with Salmonella enteritidis, in combination with an induced molt, on serum levels of the acute phase protein, alpha1 acid glycoprotein, in hens. Poultry Science, 81: 12951300.

Koolhaas, J.M. (2008) Coping style and immunity in animals: Making sense of individual variation. Brain, Behavior, and Immunity, 22: 662-667.

Littell, R.C., Henry, P.R. \& Ammerman, C.B. (1998) Statistical analysis of repeated measures data using SAS procedures. Journal of Animal Science, 76: 12161231.

Millman, S.T. (2007) Sickness behaviour and its relevance to animal welfare assessment at the group level. Animal Welfare, 16: 123-125.

Revolledo, L., Ferreira, C.S.A. \& Ferreira, A.J.P. (2009) Prevention of Salmonella Typhimurium colonization and organ invasion by combination treatment in broiler chicks. Poultry Science, 88: 734-743.

Severino, R. (2000) Proc Freq: It's more than counts. SUGI, Indianapolis, IN, pp. 6925 . 


\section{SUB CLINICAL INFECTION WITH SALMONELLA}

Tilquin, P., Barrow, P.A., Marly, J., Pitel, F., Plisson-Petit, F., Velge, P., Vignal, A., Baret, P.V., Bumstead, N. \& Beaumont, C. (2005) A genome scan for quantitative trait loci affecting the Salmonella carrier-state in the chicken. Genet Sel Evol, 37: 539-561.

Wasser, S.K., Hunt, K.E., Brown, J.L., Cooper, K., Crockett, C.M., Bechert, U., Millspaugh, J.J., Larson, S. \& Monfort, S.L. (2000) A generalized fecal glucocorticoid assay for use in a diverse array of nondomestic mammalian and avian species. General and Comparative Endocrinology, 120: 260-275.

Webster, J.I. \& Sternberg, E.M. (2004) Role of the hypothalamic-pituitary-adrenal axis, glucocorticoids and glucocorticoid receptors in toxic sequelae of exposure to bacterial and viral products. Journal of Endocrinology, 181: 207221.

Wigley, P., Hulme, S.D., Bumstead, N. \& Barrow, P.A. (2002) In vivo and in vitro studies of genetic resistance to systemic salmonellosis in the chicken encoded by the SAL1 locus. Microbes and Infection, 4: 1111-1120.

Xavier, R.J. \& Rioux, J.D. (2008) Genome-wide association studies: a new window into immune-mediated diseases. Nature Reviews. Immunology, 8: 631-643. 
SUB CLINICAL INFECTION WITH SALMONELLA

Table 1. Strain differences in resource competition tests during the preinfection period

\begin{tabular}{|c|c|c|c|c|c|c|c|}
\hline \multirow[b]{2}{*}{ Behaviour $^{\dagger}$} & \multicolumn{5}{|c|}{ Genetic strain } & & \multirow[b]{2}{*}{ Pooled SE } \\
\hline & $\mathrm{P}$ & & 0 & & $\mathrm{~N}$ & & \\
\hline $\begin{array}{l}\text { Pecking worms, } n= \\
24 / \text { strain }\end{array}$ & 1.3 & a & 3.4 & $\mathrm{~b}$ & 3.6 & $\mathrm{~b}$ & 0.6 \\
\hline Drinking, $n=24 /$ strain & 1.43 & a & 0.3 & $\mathrm{~b}$ & 0.2 & $\mathrm{~b}$ & 0.5 \\
\hline
\end{tabular}

${ }^{\mathrm{ab}}$ Values in a row not sharing a common superscript are significantly different | $(\underline{P}<0.05)$

${ }^{\dagger}$ Units are the total number of times per $15 \mathrm{~min}$ the behaviour was performed during the three pre-infection competition tests.

Deleted: O

Deleted: $p$

Formatted: Font: Italic 


\section{SUB CLINICAL INFECTION WITH SALMONELLA}

Table 2. Behaviours revealing a difference between pre- and post-infection periods during

\begin{tabular}{|c|c|c|c|c|}
\hline Treatment $^{*}$ & Behaviour & $t$-value & Probability & $\begin{array}{l}\text { Difference between } \\
\text { pre- and post- } \\
\text { infection }\end{array}$ \\
\hline SAL & Drinking & 2.68 & 0.01 & 0.343 \\
\hline SAL & Feeding on pellets & 4.45 & $<0.0001$ & 0.451 \\
\hline SAL & Litter pecks & 3.00 & 0.01 & 1.235 \\
\hline SAL & Pecking at waxworms & -2.79 & 0.01 & -0.980 \\
\hline $\mathrm{CON}$ & Feeding on waxworms & -2.22 & 0.03 & -0.314 \\
\hline
\end{tabular}

Units are the total number of times per $15 \mathrm{~min}$ the behaviour was performed during the three post-infection competition tests subtracted from the total during the three preinfection tests. Positive values indicate behaviours were performed more in the preinfection compared to the post-infection period. 
SUB CLINICAL INFECTION WITH SALMONELLA

3

Table 3. Faecal glucocorticoid metabolite concentrations (ng of

1 metabolite/g of faeces) in salmonella and control treatments before and after Salmonella challenge at day 0

\begin{tabular}{|cccccccc}
\hline & \multicolumn{9}{c}{ Treatment } \\
\cline { 2 - 6 } $\begin{array}{l}\text { Day relative } \\
\text { to infection }\end{array}$ & \multicolumn{4}{c}{ SAL* } & \multicolumn{1}{c}{ CON } & \\
\hline-13 & 0.40 & \pm & 0.09 & 0.55 & \pm & 0.14 & 0.04 \\
-6 & 0.44 & \pm & 0.09 & 0.50 & \pm & 0.07 & 0.4 \\
+1 & 0.33 & \pm & 0.08 & 2.09 & \pm & 1.20 & $>0.0001$ \\
+8 & 0.78 & \pm & 0.18 & 0.59 & \pm & 0.15 & 0.3 \\
\hline SAL, salmonella infected; CON, control.
\end{tabular}

SAL, salmonella infected; CON, control. 


\section{SUB CLINICAL INFECTION WITH SALMONELLA}

Table 4. Absorbance (490 nm) indicating antigen-specific immunoglobulin $M$ concentrations for each treatment and strain at postmortem ( +15 dpi) following a Salmonella challenge

\begin{tabular}{|c|c|c|c|c|c|c|c|c|c|}
\hline \multirow[b]{2}{*}{ Strain } & \multicolumn{8}{|c|}{ Treatment } & \multirow{2}{*}{$\begin{array}{c}P- \\
\text { value }^{\dagger}\end{array}$} \\
\hline & & & & & & $\mathrm{CO}$ & & & \\
\hline $\mathrm{P}$ & 1.85 & \pm & 0.40 & a & 0.27 & \pm & 0.05 & $\mathrm{a}$ & $<0.0001$ \\
\hline $\mathrm{O}$ & 1.75 & \pm & 0.34 & $\mathrm{a}$ & 0.23 & \pm & 0.04 & a & $<0.0001$ \\
\hline $\mathrm{N}$ & 0.98 & \pm & 0.20 & b & 0.24 & \pm & 0.05 & a & $<0.0001$ \\
\hline
\end{tabular}

${ }^{\dagger} P$-value denotes comparison for treatments

${ }^{\mathrm{ab}}$ Values within a column not sharing a common superscript are

Formatted: Font: Italic significantly different $(P<0.0001)$ 
1

Table 5. Absorbance (490 $\mathrm{nm}$ ) indicating antigen-specific immunoglobulin $Y$ concentrations for each treatment and genetic strain at post-mortem examination

\begin{tabular}{|c|c|c|c|c|c|c|c|c|c|}
\hline \multirow{3}{*}{$\begin{array}{l}\text { Strain } \\
\mathrm{P}\end{array}$} & \multicolumn{8}{|c|}{ Treatment } & \multirow{3}{*}{$\frac{P \text {-value }}{<0.0001}$} \\
\hline & \multicolumn{3}{|c|}{ SAL } & \multirow[b]{2}{*}{$\mathrm{a}$} & \multicolumn{4}{|c|}{$\mathrm{CON}$} & \\
\hline & 1.14 & \pm & 0.36 & & 0.35 & \pm & 0.10 & $\mathrm{a}$ & \\
\hline $\mathrm{O}$ & 0.93 & \pm & 0.26 & a & 0.41 & \pm & 0.11 & a & $<0.0001$ \\
\hline $\mathrm{N}$ & 0.56 & \pm & 0.17 & $\mathrm{~b}$ & 0.43 & \pm & 0.13 & $\mathrm{a}$ & 0.09 \\
\hline
\end{tabular}

${ }^{\dagger} P$-value denotes comparison for treatments

${ }^{\mathrm{ab}}$ Values within a column not sharing a common superscript are significantly different $(P<0.002)$ 


\section{SUB CLINICAL INFECTION WITH SALMONELLA}

\begin{tabular}{|c|c|c|c|c|c|c|c|}
\hline \multirow[b]{2}{*}{ Days relative to infection } & \multicolumn{6}{|c|}{ Strain } & \multirow[b]{2}{*}{ Pooled SE } \\
\hline & $\mathrm{P}$ & & $\mathrm{O}$ & & $\mathrm{N}$ & & \\
\hline$-21 \mathrm{dpi}$ & 290 & a & 334 & $\mathrm{~b}$ & 352 & $\mathrm{c}$ & 9.0 \\
\hline$-6 \mathrm{dpi}$ & 443 & a & 508 & $\mathrm{~b}$ & 562 & c & 14.5 \\
\hline change & 153 & a & 175 & b & 210 & $\mathrm{c}$ & 7.8 \\
\hline
\end{tabular}


1

\section{SUB CLINICAL INFECTION WITH SALMONELLA}

Table 7. Number of animals that were negative/positive for Salmonella at post-mortem $(+15$ dpi) within different tissue groupings for genetic line $e^{\dagger}$

\begin{tabular}{|c|c|c|c|c|c|c|c|c|}
\hline \multirow{2}{*}{$\begin{array}{l}\text { genetic } \\
\text { strain }\end{array}$} & \multicolumn{3}{|c|}{$\begin{array}{l}\text { Spleen or } \\
\text { Cecum }\end{array}$} & \multicolumn{3}{|c|}{ Spleen } & \multicolumn{2}{|c|}{ Caecum } \\
\hline & - & & + & - & & + & - & + \\
\hline$P$ & 5 & & 4 & 6 & ** & 2 & 4 & 4 \\
\hline $\mathrm{O}$ & 0 & * & 12 & 0 & $*$ & 12 & 6 & 6 \\
\hline $\mathrm{N}$ & 2 & * & 9 & 4 & & 6 & 6 & 4 \\
\hline
\end{tabular}

*Signifies a difference between number of negative and positive birds within a genetic line $(P<0.05)$.

**Signifies a trend between the number of negative and positive birds within a genetic line $(P<0.07)$.

$1{ }^{\dagger}$ Totals are different due to laboratory contamination and counts not being able to be completed. 
SUB CLINICAL INFECTION WITH SALMONELLA

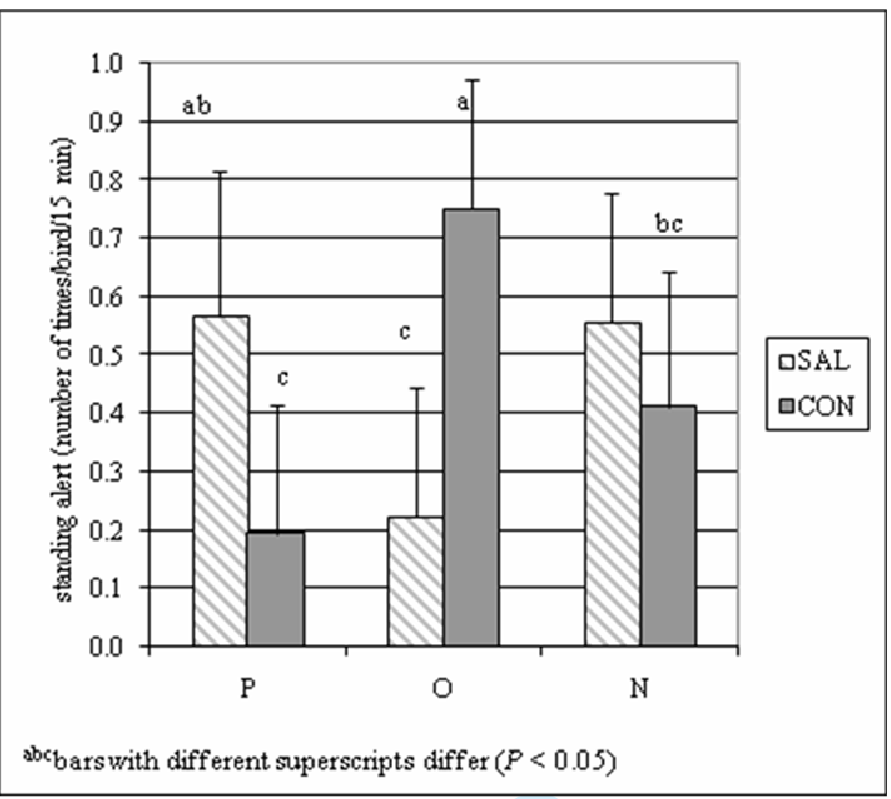




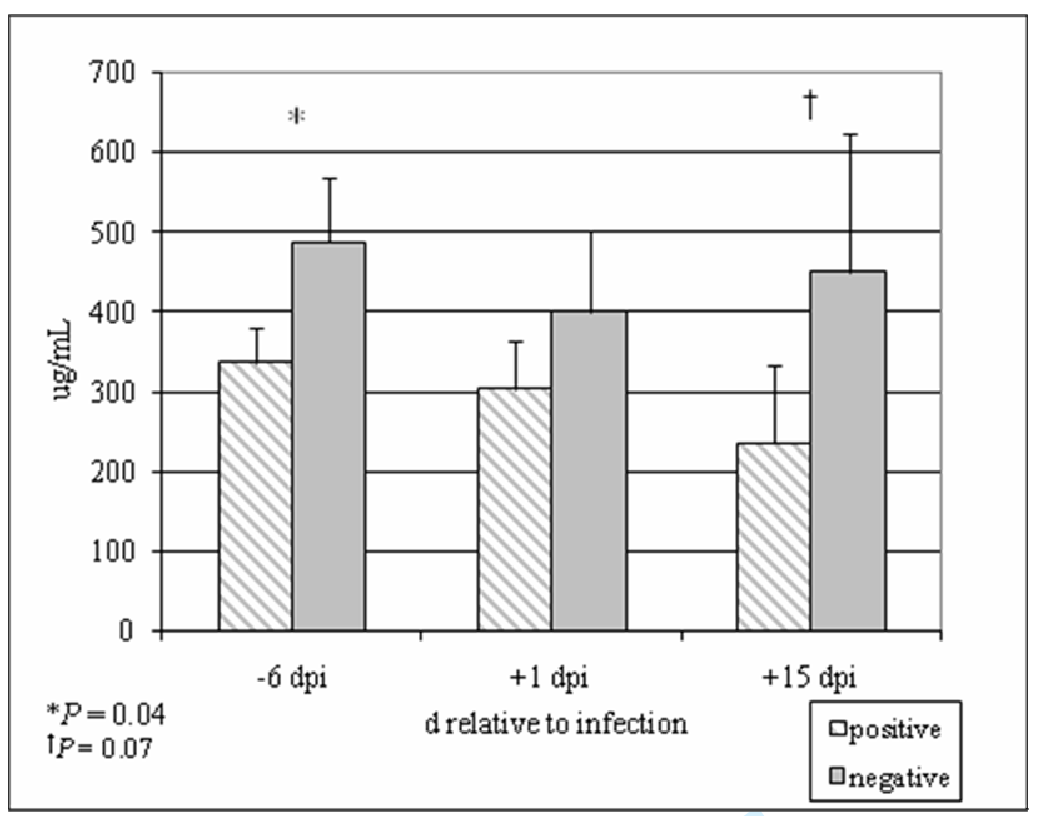


SUB CLINICAL INFECTION WITH SALMONELLA 


\section{SUB CLINICAL INFECTION WITH SALMONELLA}

Figure 1. Standing alert during the competition tests in post-infection period.

Figure 2. Concentrations of $\alpha_{1}$-acid glycoprotein for positivity grouping in the spleen before and after salmonella challenge at day 0 .

Figure 3. Concentrations of $\alpha_{1}$-acid glycoprotein for positivity grouping in the spleen and/or caecum before and after salmonella challenge at day 0. 